\title{
Use of a Refined Drug Tracer Algorithm to Estimate Prevalence and Incidence of Parkinson's Disease in a Large Israeli Population
}

\author{
Orly Chillag-Talmor ${ }^{\mathrm{a}, 1}$, Nir Giladi ${ }^{\mathrm{b}, \mathrm{c}, *}$, Shai Linn $^{\mathrm{a}, \mathrm{d}}$, Tanya Gurevich ${ }^{\mathrm{b}, \mathrm{c}}$, Baruch El-Ad ${ }^{\mathrm{e}}$, Barbara \\ Silverman ${ }^{\mathrm{e}}$, Nurit Friedman ${ }^{\mathrm{e}}$ and Chava Peretz ${ }^{\mathrm{c}}$ \\ ${ }^{a}$ School of Public Health, University of Haifa, Haifa, Israel \\ ${ }^{\mathrm{b}}$ Movement Disorders Unit, Department of Neurology, Tel Aviv Sourasky Medical Center, Tel Aviv, Israel \\ ${ }^{\mathrm{c}}$ Sackler Faculty of Medicine, Tel Aviv University, Tel Aviv, Israel \\ ${ }^{\mathrm{d}}$ Epidemiology Unit, Rambam Medical Center, Haifa, Israel \\ e Maccabi Healthcare Services, Tel Aviv, Israel
}

\begin{abstract}
Estimating rates of Parkinson's disease (PD) is essential for health services planning and studies of disease determinants. However, few PD registries exist. We aimed to estimate annual prevalence and incidence of PD in a large Israeli population over the past decade using computerized drug purchase data.

Based on profiles of anti-parkinsonian drugs, age at first purchase, purchase density, and follow-up time, we developed a refined algorithm for PD assessment (definite, probable or possible) and validated it against clinical diagnoses. We used the prescription database of the second largest Health Maintenance Organization in Israel (covers $~ 25 \%$ of population), for the years 1998-2008. PD rates by age, gender and year were calculated and compared using Poisson models.

The algorithm was found to be highly sensitive (96\%) for detecting PD cases. We identified 7,134 prevalent cases $(67 \%$ definite/probable), and 5,288 incident cases (65\% definite/probable), with mean age at first purchase $69 \pm 13$ years. Over the years 2000-2007, PD incidence rate of 33/100,000 was stable, and the prevalence rate increased from 170/100,000 to 256/100,000. For ages $50+, 60+, 70+$, median prevalence rates were $1 \%, 2 \%, 3 \%$, respectively. Incidence rates also increased with age $(\mathrm{RR}=1.76$, 95\% CI 1.75-1.77, ages 50+, 5-year interval). For ages 50+, rates were higher among men for both prevalence $(\mathrm{RR}=1.38$, 95\% CI 1.37-1.39) and incidence ( $\mathrm{RR}=1.45,95 \% \mathrm{CI} 1.42-1.48)$. In conclusion, our refined algorithm for PD assessment, based on computerized drug purchases data, may be a reliable tool for population-based studies. The findings indicate a burden of PD in Israel higher than previously assumed.
\end{abstract}

Keywords: Parkinson's disease, Parkinson's disease drug therapy, prevalence, incidence, drug tracer

\footnotetext{
${ }^{1}$ In partial fulfillment of the requirements for the $\mathrm{PhD}$ degree, University of Haifa, Israel.

*Correspondence to: N. Giladi, Department of Neurology, Tel Aviv Sourasky Medical Center, 6 Weizmann Street, Tel Aviv 64239, Israel. Tel.: +972 (0)3 6974790; Fax: +972 (0)3 6974153; E-mail: nirg@tasmc.health.gov.il.
}

\section{INTRODUCTION}

Prevalence and incidence estimates of Parkinson's disease (PD) are essential for health services planning and as a basis for studies of risk factors and potential disease modifying interventions. While regional registries are the most accurate tool to follow PD morbidity, few are currently in operation (e.g., Nebraska 
[1], California [2], and European [3] registries). PD rates reported from ad-hoc observational studies vary greatly due to differences in design and case definition [4-7]. The two classically-used designs to assess PD rates, door-to-door surveys and clinic based studies (i.e., of patients that have received medical attention, using combined sources of information, e.g., clinical records, medical claims, etc.), are costly and time-consuming. Lack of long-term follow-up in doorto-door studies impairs accuracy of PD diagnosis, while PD documentation in medical records may be inconsistent or inaccurate $[5,7]$. Computerized pharmacy purchasing databases are a relatively new and reliable source of information, which enable utilization of drug tracer methodology to estimate PD occurrence based on consumption of specific anti-parkinsonian drugs (APD) [8-11]. APD as a group, specifically the dopaminergic agents (Anatomical Therapeutic Chemical classification system (ATC) code N04B) [12], are prescribed to all PD-diagnosed patients at some disease stage, and rather selectively for parkinsonism in general [8]. The accuracy of rate estimates using drug tracing depends on data completeness and casedefinition criteria. Only few studies previously used this approach. Some employed aggregated purchase data, estimating the number of PD cases based on total APD sales divided by projected per-person utilization $[8,13,14]$. Others used person-level data, but defined a PD case as any person with at least one APD purchase $[10,11]$.

The present study is based on the prescription database of the second largest Health Maintenance Organization (HMO) in Israel. Our aims were (1) to develop and validate a refined drug-tracer algorithm for assessment of PD cases at three levels of accuracy - definite, probable and possible - based on patterns of drug consumption, age and follow-up period; and (2) to estimate the prevalence and incidence of PD in this large Israeli population over the past decade.

\section{PATIENTS AND METHODS}

\section{Design and study population}

We conducted a retrospective cohort study of the members of Maccabi Healthcare Services (MHS) over 1.8 million people nationwide $(\sim 25 \%$ of the total population), for the period 1.1.1998-31.12.2008. Since January 1998, computer systems have captured all pharmacy purchases covered by MHS. Each purchase record includes the member's identification number (ID), purchase date and drug specifications. In Israel, almost all APD are substantially subsidized for PD patients through the National Health Plan. Thus, little incentive exists for patients to purchase medications outside the plan, and we could assume nearly complete capture of the drug purchases of interest. APD are dispensed for only one month of treatment, hence we assumed each purchase represented treatment for the following month. Treatment initiation served as proxy for time of diagnosis.

Demographic characteristics of subjects - gender, birth date, membership start-date and current status at MHS (active/deceased/transferred to another HMO) were derived from MHS membership files.

\section{Algorithm for PD assessment}

We developed a refined drug-driven algorithm (Appendix 1) to assess PD patients at three accuracy levels - definite, probable and possible, based on the fact that PD therapy is chronic and generally involves increasing number of drug-types and dosages with disease progression. Thus, those levels of accuracy were assigned based on specific combinations of categories of four factors: (a) APD types used; (b) age at first APD purchase (c) follow-up period (FUP); and (d) APD purchase intensity - number and continuity of purchases, as follows:

\section{Anti-parkinsonian drugs (APD)}

We employed dopaminergic APD (ATC code N04B) as tracers (see Appendix 2 for included medications). We excluded anticholinergic agents (ATC code N04A), since they are frequently used in Israel for indications other than primary PD (e.g., neuroleptic-induced parkinsonism), and only few PD patients are treated exclusively with anticholinergics for a long period of time [15]. Selected drugs were categorized into seven groups according to mechanisms of action and clinical use (Appendix 2). Purchases of specific groups or combination of groups were supportive of PD diagnosis accuracy. Subjects who purchased only bromocriptine and were most likely treated for non-PD indications (e.g. hyperprolactinemia or termination of lactation) were excluded (criteria shown in Fig. 1).

\section{Age at first purchase}

We included only subjects aged 20-84 years at first recorded purchase to exclude cases of juvenile parkinsonism, and elderly people who are often prescribed levodopa or amantadine empirically for slowness or gait and postural disturbances. Further, in combination with purchase patterns, three categories of age at 


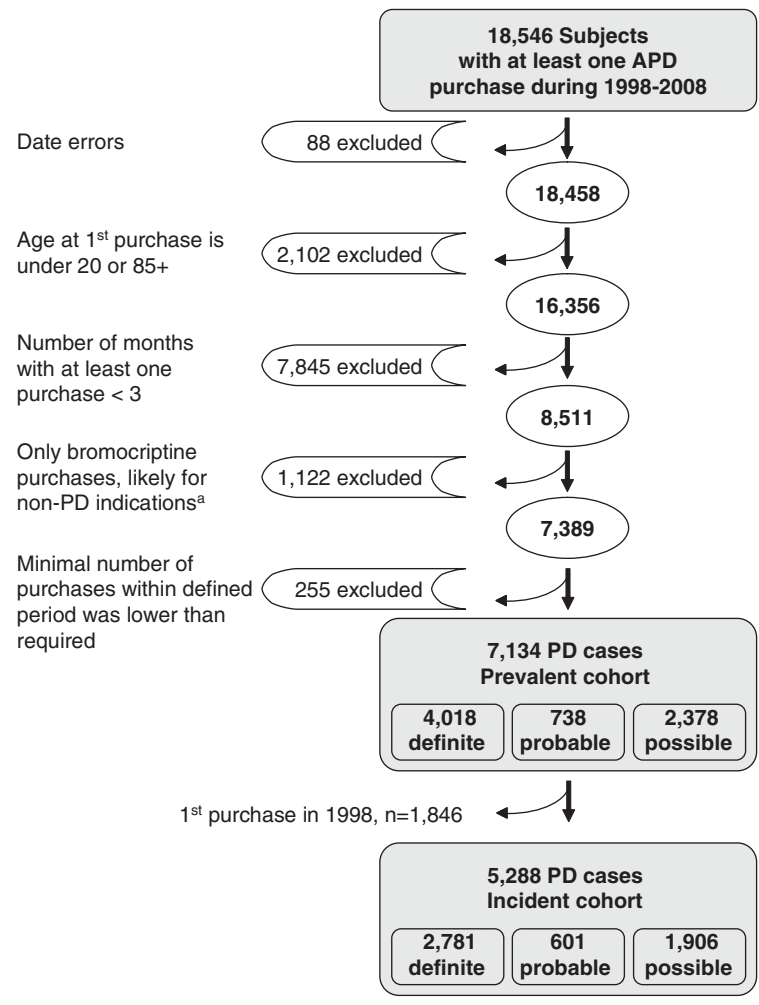

Fig. 1. Selection criteria for prevalent and incident PD cases. APD - anti-parkinsonian drugs. ${ }^{a}$ Excluded: women with age at 1st purchase $<50$, subjects with $\geq 1$ year between last purchase and end of follow-up, subjects with 1st purchase after 2002 (PD treatment initiation with bromocriptine unlikely due to availability of new dopamine agonists).

first purchase were taken into account in PD assessment - less than 65, 65-74 and 75-84 - assuming that the likelihood of initiating APD treatment for non-PD (misdiagnosis/empiric treatment) increases with age at first purchase [16].

\section{Follow-up period (FUP)}

FUP was calculated as time elapsed from date of first APD purchase to the earliest of the following dates: end of study (31.12.2008), transfer out of MHS, or death. FUP was categorized as "long" ( $\geq 3$ years) or "short" ( $<3$ years). Longer FUP was considered supportive of PD diagnosis accuracy. This concept is backed by reports that clinical follow-up of three years or more, particularly by a movement disorders specialist, improves the accuracy of the clinical diagnosis in clinical-pathological confirmation studies [17-19].

\section{Purchase intensity}

A "purchase month" was defined as a month in which at least one purchase was made. The number of purchase months of any drug and of each APD group was calculated for consecutive, 12-months long, segments of FUP. For initial inclusion, at least three purchase months during the entire FUP were necessary. Furthermore, we required at least one FUP-segment with a minimum of three purchase months (this criterion was modified for short FUP cases, see Appendix 1). The algorithm accounted for both number of purchase months and purchase continuity (i.e., number of purchase months per time observed) in assigning PD accuracy level.

\section{Characteristics of cases assigned a definite level of accuracy}

Following are the major algorithm principles for assigning a definite accuracy level (full algorithm details appear in Appendix 1). For subjects with "long" FUP ( $\geq 3$ years), criteria were applied to the set of three consecutive years with the highest purchase density, and cases were defined as definite if records showed: high purchase intensity (e.g., 9 purchase months out of 12) of either levodopa or dopamine agonists or monoamine oxidase inhibitors (MAOB-I) (the latter conditioned by age at first purchase $<75)$, OR; extended purchase intensity (18/24 months) of either amantadine or MAOB-I (the latter conditioned by age at first purchase $\geq 75$ ), OR; simultaneous purchase of a combination of APD types (6/12 months). For subjects with "short" FUP, criteria were applied to the entire FUP. Cases were defined as definite if: they fulfilled the long-FUP criteria for a definite accuracy level, OR; they fulfilled the long-FUP criteria for a probable accuracy level, conditioned by age at first purchase $\leq 65$ and purchase of either levodopa or dopamine agonists or MAOB-I.

\section{Selection of eligible patients for the PD cohorts}

The prevalent PD cohort included all patients who met the algorithm criteria during 1998-2008. The incident PD cohort excluded cases whose first purchase was during 1.1.1998-31.12.1998, who may have been treated prior to study initiation (Fig. 1).

\section{Validation of PD assessment by the algorithm}

We compared our algorithm-derived identification of PD cases to diagnoses from a specialist outpatient clinic in a tertiary medical center - the Movement Disorders Unit (MDU) in the Tel Aviv Sourasky Medical Center (TASMC). All four neurologists on the team specialize in movement disorders, and have been 
working in MDU over ten years; thus the TASMCMDU diagnoses were considered the gold standard [19]. Diagnoses of MHS members who visited MDU between mid-2003 and 2008 were retrieved from the MDU electronic records and linked by ID to the algorithm-driven PD assessment: patients with MDU diagnosis of PD were employed to calculate sensitivity of the algorithm (true positive rate), and patients with other diagnoses (parkinsonism, gait disorders, essential tremor and non PD-related dyskinesia/spasticity) were employed to calculate the false positive rate of the algorithm within this patient population.

\section{Data analysis}

Annual PD prevalence and incidence rates (per 100,000), overall and gender- and age-specific, were calculated for the years 2000-2007, since MHS membership data by age and gender were available as of 2000. The year 2008 was not included because our algorithm was less likely to identify cases diagnosed later in the study period, due to shorter follow-up time. Prevalence was based on number of PD patients active in MHS on December 31st of each calendar year; annual incidence referred to PD patients making their first purchase during the calendar year.

Poisson regression models were applied to study the effect (RR and 95\% CI) of gender, age category (5year intervals) and calendar year on annual prevalence and incidence rates of PD, for the entire group and for patients aged $50+, 60+$ and $70+$.

Although representing a broad cross-section of the Israeli population, MHS population is younger. Thus, we estimated the number of prevalent and incident PD cases for the entire Israeli population in 2005 based on the calculated prevalence/incidence rates and on the national gender- and age-distribution [20].

\section{Ethics}

The study was approved by the Institutional Review Boards (IRBs) of both TASMC and MHS. It was based on anonymous databases and involved no direct interaction with patients, thus the IRBs approved that informed consent was not required.

\section{RESULTS}

Study population: PD cohorts, 1998-2008

Based on 499,629 APD prescriptions dispensed to 18,546 MHS members between 1.1.1998 and 31.12.2008, a cohort of 7,134 prevalent PD cases was identified by our algorithm (Fig. 1). We excluded 11,412 subjects for the following reasons: apparent errors in purchase dates, or age at first purchase less than 20 or over 84 years $(2,190)$; fewer than 3 purchase months $(7,845)$; probable treatment with bromocriptine for other indications $(1,122)$; and fewer than the minimum purchase months required within an FUP segment (255). Among the 7,134 cases of the PD prevalent cohort, $56 \%(\mathrm{n}=4,018)$ were identified as definite and $11 \%$ as probable cases. The incident cohort included 5,288 cases over the entire study period with distribution of accuracy level similar to that of the prevalent cohort (Table 1).

\section{Algorithm validation}

Of $625 \mathrm{MDU}$ patients (with different diagnoses) identified, 621 (99\%) were confirmed by MHS as members. For MDU patients diagnosed with idiopathic PD, the algorithm sensitivity was $96 \%$ (179/186). The algorithm's false positive rate among patients with other movement disorders varied across different diagnoses: $82 \%$ of parkinsonism cases were falsely identified as PD, while only $4 \%$ of patients with non PDrelated dyskinesia/spasticity syndromes received false PD identification (Appendix 3).

\section{Demographics and purchase characteristics}

Men comprised $52 \%$ of prevalent PD cases. There were more men than women among the definite and probable accuracy level, but more women in the possible accuracy level.

Mean age at first purchase was $69 \pm 13$ years, slightly older among women in the probable and definite accuracy groups. Mean number of total purchase months during the study period was $32.3 \pm 31$, and mean FUP was $5 \pm 3$ years, longer for women (5.3 years vs. 4.7). In accordance with algorithm requirements, definite PD cases had the longest FUP and the largest number of total purchase months. Distribution of gender and age at first purchase in the incident cohort were similar to those of the prevalent cohort (Table 1).

\section{Sensitivity analyses}

Changing the inclusion criterion of minimum purchase months during the study period from three to four, or changing the cutoff point for long/short FUP from three to two years had negligible or no effect on accuracy level distribution, mean age at first purchase and purchase characteristics distribution.

Exclusion of all subjects who purchased only dopamine agonists $(n=186,2.6 \%)$, in order to con- 
Table 1

Characteristics of prevalent (A) and incident (B) PD cases by gender and accuracy level, 1998-2008 ${ }^{\mathrm{a}}$

\begin{tabular}{|c|c|c|c|c|c|c|c|}
\hline & \multirow[t]{2}{*}{ Accuracy level } & \multicolumn{3}{|c|}{ A. prevalent cases $(n=7134)$} & \multicolumn{3}{|c|}{ B. incident cases $(n=5288)$} \\
\hline & & men & women & total & men & women & total \\
\hline \multirow[t]{4}{*}{$n(\%)$} & definite & $2179(59)$ & $1839(54)$ & $4018(56)$ & $1533(55)$ & $1248(50)$ & $2781(53)$ \\
\hline & probable & 404 (11) & 334 (10) & 738 (11) & $329(12)$ & $272(11)$ & $601(11)$ \\
\hline & possible & $1126(30)$ & $1252(36)$ & $2378(33)$ & $923(33)$ & 983 (39) & $1906(36)$ \\
\hline & total & $3709(100)$ & $3425(100)$ & 7134 (100) & $2785(100)$ & $2503(100)$ & $5288(100)$ \\
\hline \multirow{4}{*}{$\begin{array}{l}\text { age at } 1^{\text {st }} \text { purchase, } \\
\text { mean }(\mathrm{SD})\end{array}$} & definite & $69.6(10.8)$ & $70.3(11.1)$ & $69.9(11.0)$ & $69.4(11.1)$ & $70.6(10.8)$ & $69.9(11.0)$ \\
\hline & probable & $69.6(11.4)$ & $70.9(10.6)$ & $70.2(11.1)$ & $68.7(11.8)$ & $70.2(10.8)$ & $69.4(11.4)$ \\
\hline & possible & $68.9(14.3)$ & $65.5(18.0)$ & $67.1(16.4)$ & $69.2(14.3)$ & $67.9(16.2)$ & $68.5(15.3)$ \\
\hline & total & $69.4(12.1)$ & $68.6(14.2)$ & $69.0(13.1)$ & $69.2(12.3)$ & $69.5(13.2)$ & $69.4(12.8)$ \\
\hline \multirow{4}{*}{$\begin{array}{c}\text { follow-up time from } \\
1^{\text {st }} \text { purchase in } \\
\text { years, mean }(\mathrm{SD})\end{array}$} & definite & $5.4(3.1)$ & $5.8(3.2)$ & $5.6(3.1)$ & $4.5(2.5)$ & $4.7(2.5)$ & $4.6(2.5)$ \\
\hline & probable & $3.1(2.6)$ & $3.5(2.7)$ & $3.3(2.6)$ & $2.8(2.3)$ & $3.2(2.4)$ & $3.0(2.3)$ \\
\hline & possible & $3.9(3.2)$ & $5.0(3.6)$ & $4.5(3.4)$ & $3.4(2.7)$ & $4.1(2.9)$ & $3.7(2.8)$ \\
\hline & total & $4.7(3.2)$ & $5.3(3.3)$ & $5.0(3.3)$ & $3.9(2.6)$ & $4.3(2.7)$ & $4.1(2.7)$ \\
\hline \multirow{4}{*}{$\begin{array}{l}\text { total purchase } \\
\text { months, mean } \\
\text { (SD) }\end{array}$} & definite & $48.0(31.2)$ & $48.2(31.0)$ & $48.1(31.1)$ & $39.2(23.5)$ & $39.1(23.4)$ & $39.2(23.4)$ \\
\hline & probable & $17.5(13.8)$ & $18.9(14.2)$ & $18.2(14.0)$ & $16.6(12.7)$ & $18.1(13.3)$ & $17.3(13.0)$ \\
\hline & possible & $10.4(15.0)$ & $9.4(10.9)$ & $9.9(13.0)$ & $8.5(9.2)$ & $7.9(7.0)$ & $8.2(8.1)$ \\
\hline & total & $33.3(31.2)$ & $31.1(30.4)$ & $32.3(30.9)$ & $26.3(23.6)$ & 24.6 (23.) & $25.5(23.4)$ \\
\hline
\end{tabular}

${ }^{a}$ Characteristics distribution was similar for the prevalent and incident cases of 2000-2007, which were included in the rates calculations.

trol for potential bias due to inclusion of patients with restless leg syndrome, did not alter the results.

\section{Prevalence}

Annual prevalence rates increased from 170/ 100,000 in 2000 to $256 / 100,000$ in 2007 (Table 2A), $6 \%$ per year $(\mathrm{RR}=1.06,95 \% \mathrm{CI}=1.04-1.08$, genderadjusted). When considering only the definite cases, prevalence rate increased by $5 \%$ per year $(\mathrm{RR}=1.05$, $95 \% \mathrm{CI}=1.03-1.06$, gender-adjusted). Figure 2 presents the increase in prevalence rates over time of the definite PD cases vs. all cases, demonstrating a similar trend (accounting for the under-estimation in the last study years due to our criteria for a definite case which depends on longer FUP). We found that the increase in prevalence rate varied significantly across different age groups (significant age* year interaction effect, $\mathrm{p}<0.01$, in a hierarchical model which included also year, age and gender as main effects), e.g., it was $4 \%$ for ages $35-55,2 \%$ for ages $55-85$, and $13 \%$ for ages $85+$. Exclusion of the 85+ age group yielded annual prevalence rates that increased by $5 \%$ per year $(\mathrm{RR}=1.05,95 \% \mathrm{CI}=1.03-1.06$, gender-adjusted).

Prevalence rate significantly increased with age: median annual rate was $1.0 \%$ for population aged $50+, 1.9 \%$ for ages $60+$, and $3.3 \%$ for ages $70+$. A 5 -year increment in age resulted in a $50 \%$ increase in prevalence rate $(\mathrm{RR}=1.496,95 \% \mathrm{CI}=1.493-1.499)$ (Fig. 3A, Appendix 4A).

Annual prevalence rates were somewhat higher for men compared to women, but did not differ signifi- cantly. However, in the subgroup of patients aged 50 years and up (approximately $90 \%$ of cases), prevalence rates among men were significantly higher $(\mathrm{RR}=1.38$, $95 \% \mathrm{CI}=1.37-1.39$; Fig. 3A).

Based on age- and gender-specific rates and on the age- and gender-distribution of the general Israeli population for 2005, we estimated that there were approximately 23,100 Israelis with PD that year, resulting in a standardized prevalence rate of $334 / 100,000$.

\section{Incidence}

Between 2000 and 2007, annual incidence rate remained stable at approximately 33/100,000, higher by $20 \%$ for men $(\mathrm{RR}=1.19,95 \% \mathrm{CI}=1.00-1.41)$ (Table 2B).

In a more stringently defined sub-group of incident cases (92\% of the incident cohort), from which we excluded patients who joined MHS after 1.1.1998 and made their first purchase within less than one year, the mean incidence rate was reduced to $30 / 100,000$, but the men/women ratio remained similar. Stability of the incidence rate along time was also found among the definite cases (Fig. 2).

Incidence rate increased significantly with age (Fig. 3B, Appendix 4B): over 8 years, median annual incidence rates (per 100,000) for ages $50+, 60+$ and $70+$ (up to 85) were 165, 312 and 562 respectively.

In the subgroup of incident patients aged 50 years and up at first purchase ( $~ 90 \%$ of new cases), incidence rates increased by $76 \%$ per 5 -year increment in age $(\mathrm{RR}=1.76,95 \% \mathrm{CI}=1.75-1.77)$ and were $45 \%$ higher for men $(\mathrm{RR}=1.45,95 \% \mathrm{CI}=1.42-1.48)$. 
Table 2

PD prevalence (A) and incidence (B) rates per 100,000 by gender and year, 2000-2007

\begin{tabular}{|c|c|c|c|c|c|c|c|c|c|c|c|c|}
\hline \multirow[t]{3}{*}{ Year $^{\mathrm{a}}$} & \multicolumn{6}{|c|}{ A. prevalence rate $/ 100,000$} & \multicolumn{6}{|c|}{ B. incidence rate $/ 100,000$} \\
\hline & \multicolumn{2}{|c|}{ men } & \multicolumn{2}{|c|}{ women } & \multicolumn{2}{|c|}{ total } & \multicolumn{2}{|c|}{ men } & \multicolumn{2}{|c|}{ women } & \multicolumn{2}{|c|}{ total } \\
\hline & rate & $(n)$ & rate & $(n)$ & rate & $(n)$ & rate & $(n)$ & rate & $(n)$ & rate & $(n)$ \\
\hline 2000 & 170.8 & (1232) & 168.3 & (1287) & 169.5 & (2519) & 34.2 & $(247)$ & 31.8 & $(243)$ & 33.0 & $(490)$ \\
\hline 2001 & 187.0 & (1406) & 181.4 & (1446) & 184.1 & $(2852)$ & 37.0 & $(278)$ & 29.5 & $(235)$ & 33.1 & (513) \\
\hline 2002 & 202.1 & (1557) & 198.7 & $(1625)$ & 200.4 & $(3182)$ & 36.2 & $(279)$ & 31.8 & $(260)$ & 33.9 & (539) \\
\hline 2003 & 213.5 & $(1685)$ & 211.0 & (1763) & 212.2 & (3448) & 32.4 & $(256)$ & 29.2 & (244) & 30.8 & (500) \\
\hline 2004 & 228.2 & (1844) & 230.1 & (1965) & 229.2 & (3809) & 38.9 & (314) & 34.1 & (291) & 36.4 & (605) \\
\hline 2005 & 241.3 & (1988) & 237.3 & (2064) & 239.2 & (4052) & 35.1 & (289) & 29.7 & (258) & 32.3 & $(547)$ \\
\hline 2006 & 251.1 & (2109) & 247.5 & (2192) & 249.2 & (4301) & 35.0 & (294) & 29.6 & (262) & 32.2 & $(556)$ \\
\hline 2007 & 260.6 & (2237) & 251.6 & (2275) & 256.0 & (4512) & 38.8 & (333) & 26.8 & (242) & 32.6 & (575) \\
\hline
\end{tabular}

${ }^{a}$ Prevalent cases for a specific year were cases whose follow-up period included December 31 st of that year. Incident cases for a specific year were cases whose 1st purchase occurred in that year.

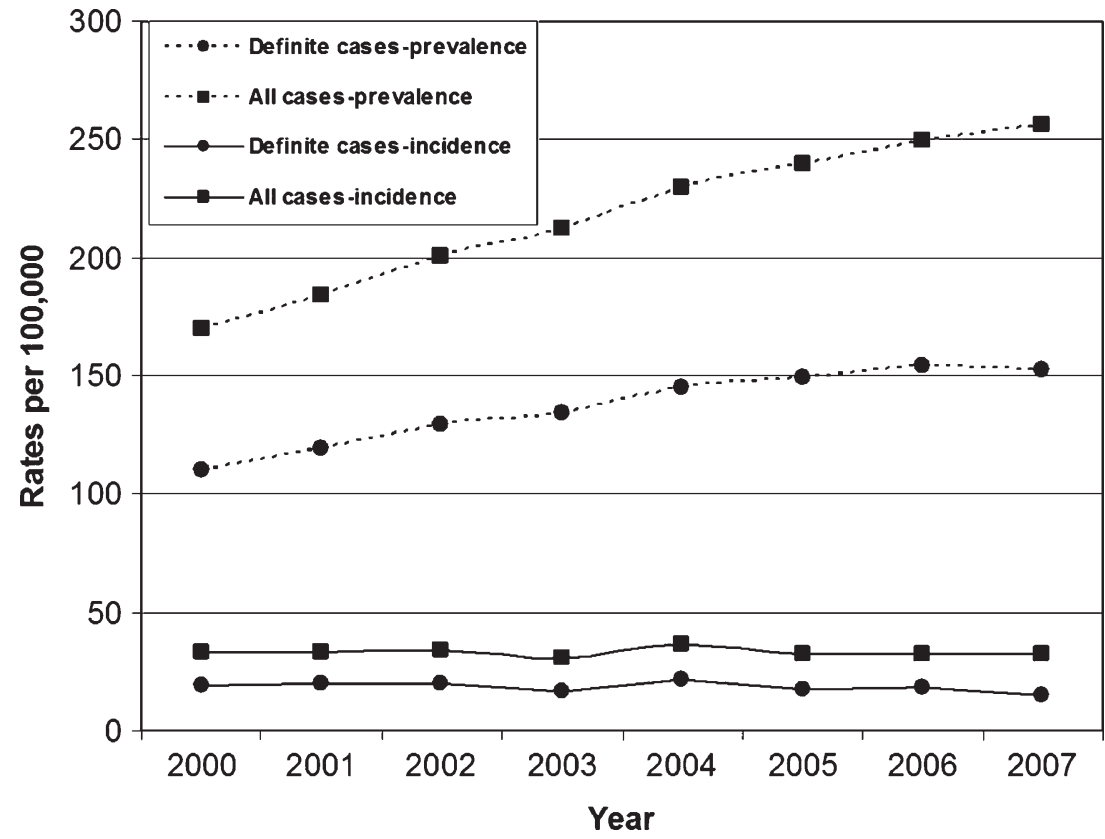

Fig. 2. PD prevalence and incidence rates per 100,000 by year, definite vs. all cases, 2000-2007. Numbers of definite cases in last years of the study period are lower than expected due to the algorithm criteria - a definite accuracy level is generally dependent on a longer follow-up period.

Based on age- and gender-specific rates and on the age- and gender-distribution of the general Israeli population for 2005, we estimated that the number of incident PD cases that year in Israel was 3,100, resulting in a standardized incidence rate of 45/100,000.

\section{DISCUSSION}

Pharmacy purchase databases are a highly valid source of drug utilization in populations with a universal drug benefit. They are very accurate and closely monitored, since they are maintained for administrative purposes. Thus, pharmacy databases enable observational studies of large populations with long follow-up, reduced selection bias and increased generalizability.
The main limitation of this approach is inclusion of patients with atypical and secondary parkinsonism who might receive APD-based treatment. This difficulty in differentiating primary PD from other parkinsonian syndromes is likely to cause overestimation of PD patients. Thus, our rates may be over-estimation of the actual numbers. Additionally, when using a drug tracing approach, undiagnosed patients or patients not treated with medications are not detectable.

In this study we developed a unique drug tracer algorithm for PD assessment, which demonstrated a very high sensitivity $(96 \%)$, and a reasonable rate of false identification of other movement disorders as PD (except for parkinsonism, as expected). Our algorithm 
A

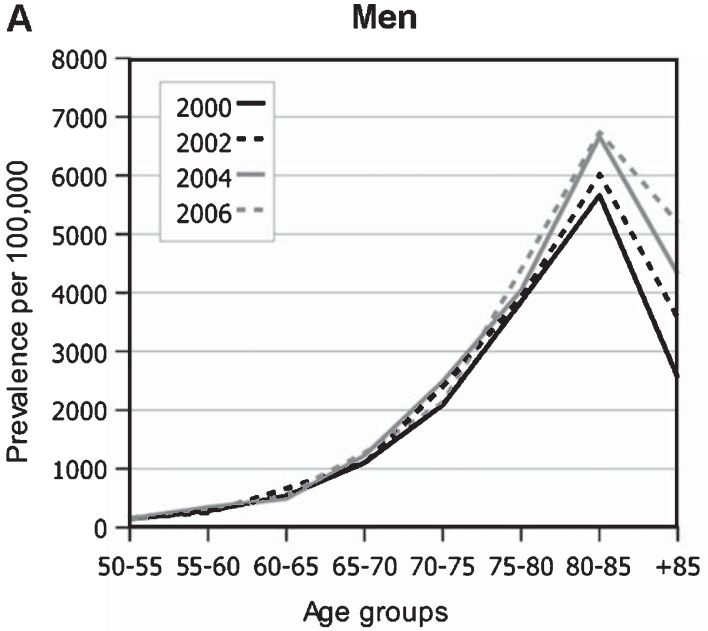

B

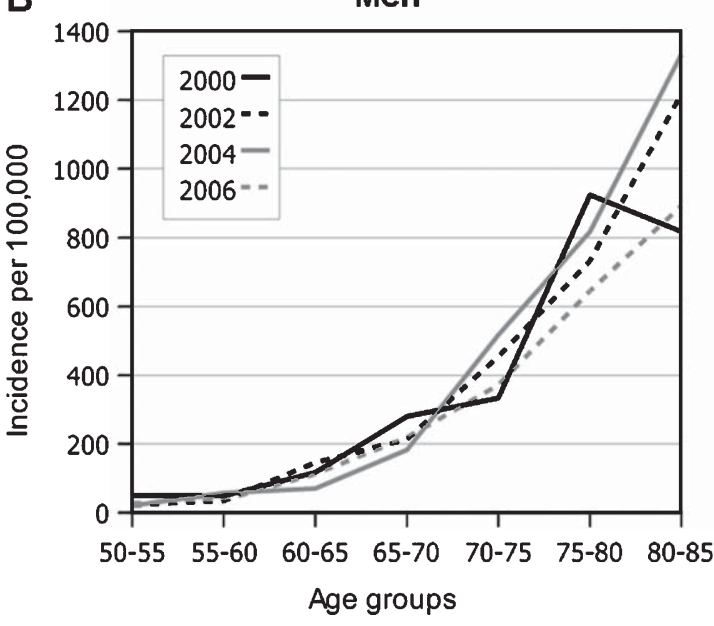

Women

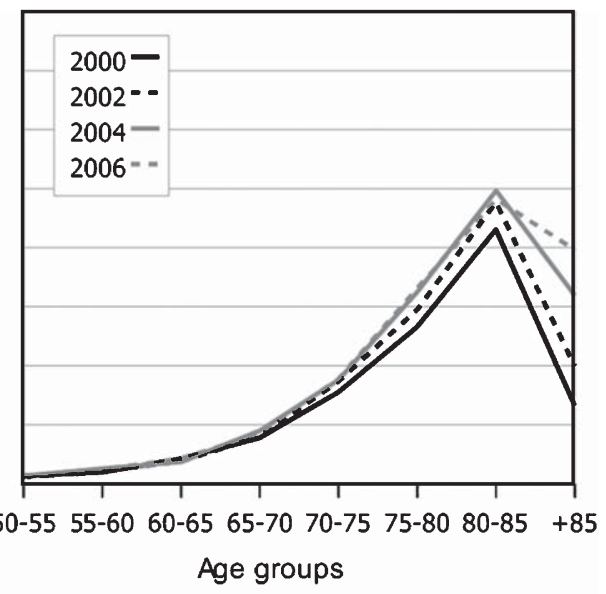

Women

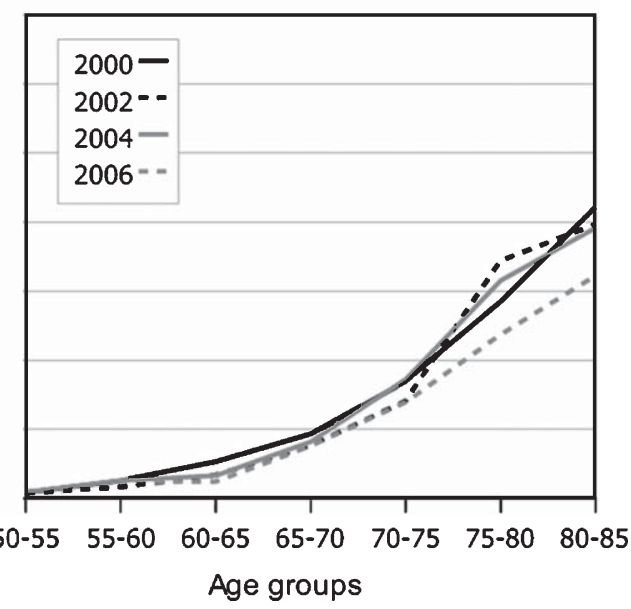

Fig. 3. PD prevalence (A) and incidence (B) rates per 100,000 by year, gender and age, 2000-2007.

also accounted for major determinants of PD diagnosis - age at first purchase and individual follow-up time, and generated individual identification of PD accuracy level. In order to reduce bias of over-identification of cases, we employed a conservative approach in constructing the algorithm that gives balanced priority to specificity, i.e., favors under-estimation. For example we used criteria such as minimum three months of purchases, exclusion of patients who began treatment at 85 years or later, purchase intensity requirements, etc. Compared with previous drug-tracer studies [9-11, 13, 14], our follow-up was long (11 vs. 2-8 years), and in addition to levodopa, a wide yet specific range of medications was used, allowing for a variety of treatment combinations.

It is clear that the algorithm we used captures incident cases quite well, demonstrating rates higher than expected, stable across the study period. Over the same period a rise in prevalence rates was observed, similar to findings of a recent Canadian study [21]. It should be noted that the increase in the prevalence rate over the study period differed significantly between the different age groups. The steep rise in the $85+$ age group was an artificial enhancement, due to algorithm criteria, thus the trend must be interpreted with caution. The increase in prevalence rate over time can be explained by a combination of factors: the long duration of PD, which is reflected in accumulation of cases; general increase in longevity (life expectancy in the general Israeli population increased by 2.8 years over the last decade [22]); and possibly improvement in medical care expressed in actual increase in disease duration. It should be considered that non-inclusion in the cohort of subjects aged $85+$ at first purchase may have caused over-estimation of the increase in prevalence over the entire study period and under-estimation of rates dur- 
ing the first study years. Our finding of an increment of parkinsonian prevalence has major impact on medical policy, but further research is needed to better understand the causes of this trend.

In accordance with previous reports, prevalence and incidence rates for ages 50 and up were significantly higher (by $\sim 40 \%$ ) among men compared to women, and increased considerably with age, with prevalence decreasing in the oldest age group [4, 6, 7, 16, 23, 24]. Age-specific rates in this study were higher than those reported in several European studies [23], e.g., the prevalence rate among persons aged 60 years or older was almost 2 -fold higher than the $1 \%$ rate traditionally cited for this age group [7].

Our adjusted estimators of PD prevalence and incidence in 2005 for the general Israeli population of $334 / 100,000$ and 45/100,000, respectively, are very high compared to other studies. For UK, Sweden, Italy, Spain, USA and other developed countries, rate ranges were: $60-350 / 100,000$ for prevalence, 5-26/100,000 for incidence [4-7, 23]. Since data about ethnic origin was unavailable from MHS databases, our estimations do not account for ethnicity, although this factor may be relevant in the mixed Israeli population: Among Ashkenazi Jews rates may be higher, due to the high frequency of PD-associated mutations in LRRK2 (G2019S) and GBA genes among this population in Israel $[25,26]$; This may account for the high occurrence we observed. However, Arab ethnicity also might be of relevance - PD prevalence rates among Israeli Arabs ( $\sim 10 \%$ of Israel's population $>50$ years) were suggested to be lower [27, 28]. Our finding of a growing population of PD patients in Israel suggests that a figure of 16,000 patients for 2005, based on extrapolation of the findings of Anca et al. in Israel [20, 29], is an under-estimate.
Mean age at first recorded purchase was 69 for both prevalent and incident cases, higher than the range 58-63 often reported in studies as age at onset/diagnosis [6], but in accordance with several population-based studies that reported age at onset between 66 and 71 [6, 24, 29-31]. Evidently, age at first medication purchase is a proxy of diagnosis age rather than onset of symptoms, and also includes a lagtime to treatment initiation, which may be longer than one year [24, 32]. The high age may also result from over-representation of patients with treatment initiation at older age, although we tried to minimize this bias by excluding cases with first purchase at 85 years of age or later, when diagnosis is very challenging and empiric treatment is common [16].

In conclusion, our proposed algorithm may be used as a reliable and low-cost tool to establish PD cohorts for epidemiological studies. Our findings of prevalence and incidence higher than expected, and a rising number of PD patients in Israel reflect the growing burden of PD morbidity on Israeli health and social systems, and should be the basis for future national resource planning.

\section{ACKNOWLEDGMENTS}

We would like to thank all members of the MDU team for their help with the validation procedure. This work was supported in part by grant SGA0902 from the Environment and Health Fund, Jerusalem, Israel. O. Chillag-Talmor received a scholarship (stipend) for research students from the University of Haifa.

\section{APPENDIX}

Appendix 1A

Algorithm for identifying PD cases and assigning them to accuracy levels (definite, probable, possible) based on drug purchase data

\begin{tabular}{ll}
\hline Definitions & Death, transfer to another HMO, or end of study (December 31st, 2008), whichever occurred first. \\
\hline Censoring & Time from 1st purchase to censoring. \\
\hline Observation segment & $\begin{array}{l}\text { The FUP is divided into consecutive observation segments of } 12 \text { months each, and a last observation segment } \\
\text { with the residual number of months. }\end{array}$ \\
\hline Purchase month & A month in which at least one purchase was made. \\
\hline Final purchase gap & Time from last purchase to censoring. \\
\hline Examined interval & $\begin{array}{l}\text { The examined interval is the period upon which most criteria are applied. For subjects with FUP } \geq 3 \text { years (long } \\
\text { FUP), the examined interval is a period of } 3 \text { consecutive, 12-months long observation segments, in which the } \\
\text { purchase intensity (sum of purchase months of drug groups 1-6) was highest (see appendix } 2 \text { for list of drugs } \\
\text { and groups). For subjects with FUP }<3 \text { years (short FUP), the examined interval is their full FUP. }\end{array}$ \\
\hline Lag to 1st purchase & $\begin{array}{l}\text { Time from the later between start of study (January 1st, 1998) and the start date of membership in MHS to 1st } \\
\text { purchase. It is assumed that a lag to 1st purchase } \geq 1 \text { year implies an actual } 1 \text { st purchase, while a lag < } 1 \text { year } \\
\text { suggests that drug purchases may have occurred prior to the 1st purchase recorded in the data employed in the } \\
\text { study (i.e., before the study began or before the subject joined MHS). }\end{array}$ \\
\hline
\end{tabular}


Appendix 1B

Full-detail algorithm. Terms defined above (section A) are italicized in the algorithm table below

\begin{tabular}{|c|c|c|c|}
\hline \multirow[t]{2}{*}{1.} & minimum 1 purchase during the study period $1.1 .1998-31.12 .2008$ & no $\longrightarrow$ & exclusion \\
\hline & \multicolumn{3}{|l|}{ yes $\downarrow$} \\
\hline \multirow[t]{2}{*}{2.} & $20 \leq$ age at 1 st purchase $<85$ & no $\longrightarrow$ & exclusion \\
\hline & \multicolumn{3}{|l|}{ yes $\downarrow$} \\
\hline \multirow[t]{2}{*}{3.} & minimum 3 purchase months within $F U P$ & no- $\longrightarrow$ & exclusion \\
\hline & \multicolumn{3}{|l|}{ yes $\downarrow$} \\
\hline \multirow[t]{2}{*}{4.} & $\begin{array}{l}\text { purchases of GR } 3 \text { only (bromocriptine) AND pattern suggesting indications other } \\
\text { than PD, namely: subjects with } 1 \text { st purchase in } 2003 \text { or later, or subjects with final } \\
\text { purchase gap } \geq 365 \text { days, or women with age at } 1 \text { st purchase }<50\end{array}$ & yes $\longrightarrow$ & exclusion \\
\hline & \multicolumn{3}{|l|}{ no $\downarrow$} \\
\hline \multirow[t]{3}{*}{5.} & $F U P \geq 3$ years & no $\longrightarrow$ & $\begin{array}{l}\text { go to step } 15, \\
\text { algorithm for } \\
\text { FUP }<3 \text { years }\end{array}$ \\
\hline & \multicolumn{3}{|l|}{ yes $\downarrow$} \\
\hline & $* * * * * * * *$ algorithm for subjects with $F U P \geq 3$ years $* * *$ & & \\
\hline \multirow[t]{2}{*}{6.} & at least 1 observation segment with a minimum of 3 purchase months & no $\longrightarrow$ & exclusion \\
\hline & yes $\downarrow$ & & \\
\hline \multirow[t]{3}{*}{7.} & at least 1 purchase month of GR 7 (apomorphine) & yes $\longrightarrow$ & $\begin{array}{l}\text { certainty level: } \\
\text { definite }\end{array}$ \\
\hline & no $\downarrow$ & & \\
\hline & Note: As of step 8, all criteria are applied to the examined interval & & \\
\hline \multirow[t]{2}{*}{8.} & During the examined interval, at least 24 purchase months of GR 1,2, 4 or 5 & yes $\longrightarrow$ & $\begin{array}{l}\text { certainty level: } \\
\text { definite }\end{array}$ \\
\hline & no $\downarrow$ & & \\
\hline \multirow[t]{2}{*}{9.} & $\begin{array}{l}\text { if age at } 1 \text { st purchase }<75 \text { : during at least } 1 \text { of the observation segments within the } \\
\text { examined interval, minimum } 9 \text { purchase months of GR } 1,2 \text { or } 4 ; \text { OR during any } 2 \\
\text { of the observation segments within the examined interval, minimum } 18 \text { purchase } \\
\text { months of GR } 5 \\
\text { if age at } 1 \text { st purchase } \geq 75 \text { : during at least } 1 \text { of the observation segments within the } \\
\text { examined interval, minimum } 9 \text { purchase months of GR } 1 \text { or } 2 ; \text { OR during any } 2 \text { of } \\
\text { the observation segments within the examined interval, minimum } 18 \text { purchase } \\
\text { months of GR } 4 \text { or } 5\end{array}$ & yes $\longrightarrow$ & $\begin{array}{l}\text { certainty level: } \\
\text { definite }\end{array}$ \\
\hline & no $\downarrow$ & & \\
\hline \multirow[t]{2}{*}{10.} & $\begin{array}{l}\text { during at least } 1 \text { of the observation segments within the examined interval, } \\
\text { minimum } 6 \text { simultaneous purchase months of drugs of } 2 \text { groups or more, any } \\
\text { combination excluding }(4+5)\end{array}$ & yes $\longrightarrow$ & $\begin{array}{l}\text { certainty level: } \\
\text { definite }\end{array}$ \\
\hline & no $\downarrow$ & & \\
\hline \multirow[t]{2}{*}{11.} & $\begin{array}{l}\text { if age at } 1 \text { st purchase }<75 \text { : during at least } 1 \text { of the observation segments within the } \\
\text { examined interval, minimum } 6 \text { purchase months of GR } 1,2 \text { or } 4 \text {, or } 9 \text { purchase } \\
\text { months of GR } 5 ; \text { OR during any } 2 \text { of the observation segments within the } \\
\text { examined interval, minimum } 16 \text { purchase months of GR } 5 \\
\text { if age at } 1 \text { st purchase } \geq 75 \text { : during at least } 1 \text { of the observation segments within the } \\
\text { examined interval, minimum } 6 \text { purchase months of GR } 1 \text { or } 2 \text {, or } 9 \text { purchase } \\
\text { months of GR } 4 \text { or } 5 ; \text { OR during any } 2 \text { of the observation segments within the } \\
\text { examined interval, minimum } 16 \text { purchase months of GR } 4 \text { or } 5\end{array}$ & yes $\longrightarrow$ & go to step 13 \\
\hline & no $\downarrow$ & & \\
\hline \multirow[t]{2}{*}{12.} & $\begin{array}{l}\text { during at least } 1 \text { of the observation segments within the examined interval, } \\
\text { minimum } 6 \text { simultaneous purchase months of drugs of GR }(4+5), \underline{\text { OR minimum } 3} \\
\text { simultaneous purchase months of drugs of } 2 \text { groups or more, any combination } \\
\text { excluding }(4+5)\end{array}$ & no- $\longrightarrow$ & go to step 14 \\
\hline & yes $\downarrow$ & & \\
\hline 13. & final purchase gap $<365$ days & yes $\longrightarrow$ & $\begin{array}{l}\text { certainty level: } \\
\text { probable }\end{array}$ \\
\hline
\end{tabular}




\begin{tabular}{|c|c|c|c|}
\hline & $\begin{array}{l}\text { Appendix 1B } \\
\text { (Continued) }\end{array}$ & & \\
\hline 14. & remaining subjects & yes $\longrightarrow$ & $\begin{array}{l}\text { certainty level: } \\
\text { possible }\end{array}$ \\
\hline & end & & \\
\hline 15. & $\begin{array}{l}\text { age at } 1 \text { st purchase } \leq 65 ; \underline{\text { OR }} \text { lag to } 1 \text { st purchase } \geq 1 \text { year and deceased during the } \\
\text { study period }\end{array}$ & yes $\longrightarrow$ & go to step 6 \\
\hline & no $\downarrow$ & & \\
\hline 16. & $\begin{array}{l}\text { at least } 1 \text { observation segment with a minimum of } 3 \text { purchase months, } \underline{\mathbf{O R}} \text { during } \\
\text { any } 2 \text { observation segments within the examined interval, minimum } 4 \text { purchase } \\
\text { months, } \mathbf{O R} \text { - for subjects with } F U P<2 \text { years - minimum } 3 \text { purchase months } \\
\text { within the entire } F U P\end{array}$ & no $\longrightarrow$ & exclusion \\
\hline & yes $\downarrow$ & & \\
\hline 17. & lag to 1 st purchase $<1$ year and deceased during the study period & yes $\longrightarrow$ & go to step 7 \\
\hline & no $\downarrow$ & & \\
\hline 18. & at least 1 purchase month of GR 7 (apomorphine) & yes $\longrightarrow$ & $\begin{array}{l}\text { certainty level: } \\
\text { definite }\end{array}$ \\
\hline & no $\downarrow$ & & \\
\hline 19. & During the examined interval, at least 24 purchase months of GR $1,2,4$ or 5 & yes $\longrightarrow$ & $\begin{array}{l}\text { certainty level: } \\
\text { definite }\end{array}$ \\
\hline & no $\downarrow$ & & \\
\hline 20. & $\begin{array}{l}\text { during at least } 1 \text { of the observation segments within the examined interval, } \\
\text { minimum } 6 \text { purchase months of GR } 1,2 \text { or } 4 ; \text { OR during any } 2 \text { of the observation } \\
\text { segments within the examined interval, minimum } 18 \text { purchase months of GR } 5\end{array}$ & yes $\longrightarrow$ & $\begin{array}{l}\text { certainty level: } \\
\text { definite }\end{array}$ \\
\hline & no $\downarrow$ & & \\
\hline 21. & $\begin{array}{l}\text { during at least } 1 \text { of the observation segments within the examined interval, } \\
\text { minimum } 6 \text { simultaneous purchase months of drugs of } 2 \text { groups or more, any } \\
\text { combination excluding (4+5), OR minimum } 3 \text { simultaneous purchase months of } \\
\text { drugs of } 2 \text { groups or more, any combination of GR } 1,2,4,6\end{array}$ & yes $\longrightarrow$ & $\begin{array}{l}\text { certainty level: } \\
\text { definite }\end{array}$ \\
\hline & no $\downarrow$ & & \\
\hline 22. & $\begin{array}{l}\text { during at least } 1 \text { of the observation segments within the examined interval, } \\
\text { minimum } 9 \text { purchase months of GR } 5 ; \text { OR during any } 2 \text { of the observation } \\
\text { segments within the examined interval, minimum } 16 \text { purchase months of GR } 5\end{array}$ & yes $\longrightarrow$ & $\begin{array}{l}\text { certainty level: } \\
\text { probable }\end{array}$ \\
\hline & no $\downarrow$ & & \\
\hline 23. & $\begin{array}{l}\text { during at least } 1 \text { of the observation segments within the examined interval, } \\
\text { minimum } 6 \text { simultaneous purchase months of drugs of GR }(4+5), \underline{\text { OR minimum } 3} \\
\text { simultaneous purchase months of drugs of } 2 \text { groups or more, any combination } \\
\text { excluding (4+5) }\end{array}$ & yes $\longrightarrow$ & $\begin{array}{l}\text { certainty level: } \\
\text { probable }\end{array}$ \\
\hline & no $\downarrow$ & & \\
\hline 24. & final purchase gap $<365$ days & no $\longrightarrow$ & go to step 26 \\
\hline & yes $\downarrow$ & & \\
\hline 25. & $\begin{array}{l}\text { at least } 1 \text { observation segment with a minimum of } 3 \text { purchase months of GR } 1,2 \text {, } \\
\text { or } 4 \mathbf{O R} \text { during any } 2 \text { observation segments within the examined interval, } \\
\text { minimum } 4 \text { purchase months and no purchases of GR } 3 \text { or } 5, \underline{\mathbf{O R}}-\text { for subjects } \\
\text { with } F U P<2 \text { years }- \text { minimum } 3 \text { purchase months within the entire FUP and no } \\
\text { purchases of GR } 3 \text { or } 5\end{array}$ & yes $\longrightarrow$ & $\begin{array}{l}\text { certainty level: } \\
\text { probable }\end{array}$ \\
\hline & no $\downarrow$ & & \\
\hline 26. & remaining subjects & yes $\longrightarrow$ & $\begin{array}{l}\text { certainty level: } \\
\text { possible }\end{array}$ \\
\hline & end & & \\
\hline
\end{tabular}


Appendix 2

Generic drug list for tracing PD patients

\begin{tabular}{|c|c|c|c|}
\hline ATC group name & ATC code & Generic name $^{\mathrm{a}}$ (drug group in study) & Mechanism of action \\
\hline \multirow[t]{2}{*}{ Dopa and dopa derivatives } & N04B A 02 & $\begin{array}{l}\text { Levodopa+carbidopa (group 1) } \\
\text { Levodopa+benserazide (group 1) }\end{array}$ & $\begin{array}{l}\text { Dopamine precursor }+ \text { inhibitor of dopa } \\
\text { decarboxylase }\end{array}$ \\
\hline & N04B A 03 & $\begin{array}{l}\text { Levodopa+carbidopa+entacapone } \\
\text { (group 1) }\end{array}$ & $\begin{array}{l}\text { Dopamine precursor + peripheral dopa } \\
\text { decarboxylase inhibitor + COMT inhibitor }\end{array}$ \\
\hline Adamantane derivatives & N04B B 01 & Amantadine (group 5) & Dopaminergic, anti-viral \\
\hline \multirow{6}{*}{ Dopamine agonists $^{\mathrm{c}}$} & N04B C 01 & Bromocriptine (group 3) & Dopamine agonist \\
\hline & N04B C 02 & Pergolide (group 2) & Dopamine agonist \\
\hline & N04B C 04 & Ropinirole (group 2) & Dopamine agonist \\
\hline & N04B C 06 & Cabergoline (group 2) & Dopamine agonist \\
\hline & N04B C 07 & Apomorphine (group 7) & Dopamine agonist \\
\hline & N04B C 10 & Lisuride (group 2) & Dopamine agonist \\
\hline \multirow{2}{*}{ MAO B inhibitors } & N04B D 01 & Selegiline (group 4) & MAO B inhibitor \\
\hline & N04B D 02 & Rasagiline (group 4) & MAO B inhibitor \\
\hline \multirow{2}{*}{$\begin{array}{l}\text { Other dopaminergic } \\
\text { agents }\end{array}$} & N04B X 01 & Tolcapone (group 6) & COMT inhibitor \\
\hline & N04B X 02 & Entacapone (group 6) & COMT inhibitor \\
\hline
\end{tabular}

COMT - catechol-O-methyltransferase; MAO - monoamine oxidase.

${ }^{\text {a }}$ All commercial preparations available during the study period were included, apart from specific preparations of amantadine (Influ- $\mathrm{A}^{\circledR}$ ) and low-dose cabergoline (Dostine ${ }^{\circledR}$, Cabotrim $^{\circledR}$ ) which are not indicated for PD in Israel.

${ }^{\mathrm{b}}$ Stalevo ${ }^{\circledR}$ was included only in Group 1 .

${ }^{\mathrm{c}}$ Pramipexole was not included as it was not available in Israel until 2009.

Appendix 3

Validation of the algorithm-driven assessment of PD patients based on drug purchases

\begin{tabular}{|c|c|c|c|c|c|}
\hline \multirow[b]{4}{*}{$\begin{array}{l}\text { Algorithm } \\
\text { assessment }\end{array}$} & \multicolumn{5}{|c|}{ Gold standard diagnosis ${ }^{\mathrm{a}}$} \\
\hline & \multirow[t]{2}{*}{ PD } & \multicolumn{4}{|c|}{ Other movement disorders } \\
\hline & & Parkinsonism $^{\mathrm{b}}$ (not PD) & Gait disorders & essential tremor & $\begin{array}{c}\text { non PD-related dyskinesia } \\
\text { or spasticity syndromes }\end{array}$ \\
\hline & & & & & \\
\hline$\overline{P D}$ & $179(96 \%)$ & $60(82 \%)$ & $16(27 \%)$ & $4(22 \%)$ & $12(4 \%)$ \\
\hline not PD & $7(4 \%)$ & $13(18 \%)$ & $44(73 \%)$ & $14(78 \%)$ & $272(96 \%)$ \\
\hline total & 186 & 73 & 60 & 18 & 284 \\
\hline
\end{tabular}

${ }^{a}$ Diagnosis was made by a movement disorders specialist from the Movement Disorders Unit at the Tel Aviv Sourasky Medical Center.

b Includes: drug-induced parkinsonism, Parkinson plus, and other parkinsonian syndromes.

Appendix 4

\begin{tabular}{|c|c|c|c|c|c|c|c|c|c|}
\hline & $\operatorname{Age}^{\mathrm{b}}$ (years) & 2000 & 2001 & 2002 & 2003 & 2004 & 2005 & 2006 & 2007 \\
\hline \multicolumn{10}{|c|}{ A. PD prevalence rates per 100,000 by year $^{\mathrm{a}}$, gender and age, $2000-2007$} \\
\hline \multirow[t]{8}{*}{ Men } & $50-55$ & 144 & 151 & 158 & 170 & 147 & 146 & 157 & 170 \\
\hline & $55-60$ & 281 & 270 & 248 & 274 & 341 & 320 & 299 & 317 \\
\hline & $60-65$ & 536 & 659 & 664 & 583 & 494 & 523 & 567 & 593 \\
\hline & $65-70$ & 1100 & 979 & 1097 & 1164 & 1222 & 1231 & 1272 & 1282 \\
\hline & $70-75$ & 2090 & 2394 & 2404 & 2351 & 2490 & 2395 & 2132 & 2079 \\
\hline & $75-80$ & 3853 & 3912 & 3923 & 3970 & 4041 & 4284 & 4400 & 4441 \\
\hline & $80-85$ & 5666 & 5656 & 6028 & 6182 & 6666 & 6947 & 6737 & 6456 \\
\hline & $85+$ & 2552 & 3184 & 3567 & 4423 & 4318 & 4661 & 5191 & 5460 \\
\hline \multirow[t]{8}{*}{ Women } & $50-55$ & 124 & 107 & 118 & 120 & 131 & 133 & 136 & 130 \\
\hline & $55-60$ & 192 & 201 & 215 & 224 & 255 & 244 & 239 & 249 \\
\hline & $60-65$ & 419 & 402 & 382 & 379 & 367 & 414 & 428 & 454 \\
\hline & $65-70$ & 775 & 789 & 797 & 832 & 898 & 881 & 836 & 788 \\
\hline & $70-75$ & 1552 & 1691 & 1735 & 1701 & 1756 & 1782 & 1778 & 1732 \\
\hline & $77-80$ & 2656 & 2738 & 2950 & 3067 & 3251 & 3230 & 3315 & 3217 \\
\hline & $80-85$ & 4307 & 4499 & 4773 & 4878 & 4968 & 4817 & 4820 & 4903 \\
\hline & $85+$ & 1325 & 1597 & 1992 & 2475 & 3186 & 3476 & 3962 & 3842 \\
\hline
\end{tabular}




\begin{tabular}{|c|c|c|c|c|c|c|c|c|c|}
\hline \multicolumn{10}{|c|}{$\begin{array}{l}\text { Appendix } 4 \\
\text { (Continued) }\end{array}$} \\
\hline & Age $^{\mathrm{b}}$ (years) & 2000 & 2001 & 2002 & 2003 & 2004 & 2005 & 2006 & 2007 \\
\hline \multicolumn{10}{|c|}{ B. PD incidence rates per 100,000 by year ${ }^{\mathrm{a}}$, gender and age, 2000-2007 } \\
\hline \multirow[t]{7}{*}{ Men } & $50-55$ & 49 & 32 & 22 & 29 & 21 & 14 & 27 & 38 \\
\hline & $55-60$ & 48 & 28 & 34 & 39 & 57 & 50 & 37 & 61 \\
\hline & $60-65$ & 116 & 194 & 145 & 118 & 71 & 89 & 113 & 111 \\
\hline & $65-70$ & 279 & 192 & 212 & 141 & 183 & 148 & 218 & 208 \\
\hline & $70-75$ & 333 & 601 & 453 & 374 & 517 & 457 & 371 & 358 \\
\hline & $75-80$ & 924 & 745 & 732 & 666 & 817 & 702 & 644 & 753 \\
\hline & $80-85$ & 817 & 1093 & 1218 & 1148 & 1333 & 1184 & 893 & 1007 \\
\hline \multirow[t]{7}{*}{ Women } & $50-55$ & 17 & 14 & 14 & 27 & 17 & 19 & 19 & 17 \\
\hline & $55-60$ & 50 & 26 & 31 & 25 & 52 & 30 & 47 & 36 \\
\hline & $60-65$ & 105 & 87 & 67 & 80 & 65 & 69 & 48 & 64 \\
\hline & $65-70$ & 185 & 141 & 153 & 133 & 164 & 103 & 152 & 111 \\
\hline & $70-75$ & 338 & 341 & 282 & 357 & 344 & 311 & 279 & 267 \\
\hline & $75-80$ & 569 & 577 & 688 & 578 & 631 & 578 & 475 & 457 \\
\hline & $80-85$ & 842 & 667 & 793 & 572 & 784 & 628 & 645 & 469 \\
\hline
\end{tabular}

${ }^{a}$ Prevalent cases for a specific year were cases whose follow-up period included December 31 st of that year. Incident cases for a specific year were cases whose 1 st purchase occurred in that year.

${ }^{\mathrm{b}}$ Data presented for cases aged 50+ on prevalence day for prevalence and on day of 1st purchase for incidence. These account for approximately $90 \%$ of all prevalent and incident cases, respectively.

\section{REFERENCES}

[1] Nebraska Department of Health \& Human Services (2007) Nebraska Parkinson's Disease Registry, 2007 http://www.hhs. state.ne.us/ced/parkinsons/, Accessed on March 23, 2008.

[2] The Parkinson's Institute (2006) California PD Registry - Legislative History, 2006. http://www.thepi.org/site/ parkinson/section.php?id=92, Accessed on March 23, 2008.

[3] Sautter J, Wick R, Adlkofer F, \& Baker MG (2003) Research in the European Union. Lancet Neurol, 2, 702-706.

[4] Zhang ZX \& Roman GC (1993) Worldwide occurrence of Parkinson's disease: an updated review. Neuroepidemiology, 12, 195-208.

[5] Checkoway H \& Nelson LM (1999) Epidemiologic approaches to the study of Parkinson's disease etiology. Epidemiology, 10, 327-336.

[6] Twelves D, Perkins KS, \& Counsell C (2003) Systematic review of incidence studies of Parkinson's disease. Mov Disord, 18, 19-31.

[7] de Lau LM \& Breteler MM (2006) Epidemiology of Parkinson's disease. Lancet Neurol, 5, 525-535.

[8] de Pedro Cuesta J \& Rosenqvist U (1984) Tracers for paralysis agitans in epidemiological research. Neuroepidemiology, $\mathbf{3}$, 82-96.

[9] Menniti-Ippolito F, Spila-Alegiani S, Vanacore N, Bonifati V, Diana G, Meco G, \& Raschetti R (1995) Estimate of parkinsonism prevalence through drug prescription histories in the Province of Rome, Italy. Acta Neurol Scand, 92, 49-54.

[10] Lai BC, Schulzer M, Marion S, Teschke K, \& Tsui JK (2003) The prevalence of Parkinson's disease in British Columbia, Canada, estimated by using drug tracer methodology. Parkinsonism Relat Disord, 9, 233-238.

[11] Brandt-Christensen M, Kvist K, Nilsson FM, Andersen PK, \& Kessing LV (2006) Use of antiparkinsonian drugs in Denmark: results from a nationwide pharmacoepidemiological study. Mov Disord, 21, 1221-1225.
[12] World Health Organization Collaborating Centre for Drug Statistics Methodology (2008) Anatomical Therapeutic Chemical Classification System with Defined Daily Dose (ATC/DDD) Index 2008. http://www.whocc.no/atcddd/, Accessed on January 30, 2008.

[13] Aquilonius SM \& Hartvig P (1986) A Swedish county with unexpectedly high utilization of anti-parkinsonian drugs. Acta Neurol Scand, 74, 379-382.

[14] Martinez-Suarez MM \& Blazquez-Menes B (2000) [Estimation of the prevalence of Parkinson's disease in Asturia, Spain. A pharmacoepidemiological study of the consumption of antiparkinson drugs]. Rev Neurol, 31, 1001-1006.

[15] National Institute for Health, Clinical Excellence (2006) Parkinson's disease: Diagnosis and management in primary and secondary care. NICE clinical guideline 35, 2006. http://www.nice.org.uk/CG035, Accessed on October 10, 2010.

[16] Kuopio AM, Marttila RJ, Helenius H, \& Rinne UK (1999) Changing epidemiology of Parkinson's disease in southwestern Finland. Neurology, 52, 302-308.

[17] Gibb WR \& Lees AJ (1988) The relevance of the Lewy body to the pathogenesis of idiopathic Parkinson's disease. J Neurol Neurosurg Psychiatry, 51, 745-752.

[18] Gelb DJ, Oliver E, \& Gilman S (1999) Diagnostic criteria for Parkinson disease. Arch Neurol, 56, 33-39.

[19] Hughes AJ, Daniel SE, Ben-Shlomo Y, \& Lees AJ (2002) The accuracy of diagnosis of parkinsonian syndromes in a specialist movement disorder service. Brain, 125, 861-870.

[20] Israel Central Bureau of Statistics (2006) Statistical abstract of Israel, 2006: Table 2.18 - Population, by population group, religion, sex and age. http://www.cbs.gov.il/reader/shnaton/ templ_shnaton.html?num_tab=st02_18\&CYear=2006, Accessed on October 29, 2009.

[21] Lix LM, Hobson DE, Azimaee M, Leslie WD, Burchill C, \& Hobson S (2010) Socioeconomic variations in the prevalence and incidence of Parkinson's disease: a population-based analysis. J Epidemiol Community Health, 64, 335-340. 
[22] Israel Central Bureau of Statistics (2010) Statistical abstract of Israel, 2010: Table 3.24 - Life expectancy, by sex, religion and population group. http://www.cbs.gov.il/ shnaton61/download/st03_24.xls, Accessed on May 8, 2011.

[23] von Campenhausen S, Bornschein B, Wick R, Botzel K, Sampaio C, Poewe W, Oertel W, Siebert U, Berger K, \& Dodel R (2005) Prevalence and incidence of Parkinson's disease in Europe. Eur Neuropsychopharmacol, 15, 473-490.

[24] Wermuth L, Bech S, Petersen MS, Joensen P, Weihe P, \& Grandjean P (2008) Prevalence and incidence of Parkinson's disease in The Faroe Islands. Acta Neurol Scand, 118, 126131.

[25] Orr-Urtreger A, Shifrin C, Rozovski U, Rosner S, Bercovich D, Gurevich T, Yagev-More H, Bar-Shira A, \& Giladi N (2007) The LRRK2 G2019S mutation in Ashkenazi Jews with Parkinson disease: is there a gender effect? Neurology, 69 , 1595-1602.

[26] Sidransky E, Nalls MA, Aasly JO, Aharon-Peretz J, Annesi G, Barbosa E.R, Bar-Shira A, Berg D, Bras J, Brice A, Chen CM, Clark LN, Condroyer C, De Marco EV, Durr A, Eblan MJ, Fahn S, Farrer MJ, Fung HC, Gan-Or Z, Gasser T, GershoniBaruch R, Giladi N, Griffith A, Gurevich T, Januario C, Kropp P, Lang A.E, Lee-Chen GJ, Lesage S, Marder K, Mata I.F Mirelman A, Mitsui J, Mizuta I, Nicoletti G, Oliveira C, Ottman R, Orr-Urtreger A, Pereira LV, Quattrone A, Rogaeva E, Rolfs A, Rosenbaum H, Rozenberg R, Samii A, Samaddar T, Schulte C, Sharma M, Singleton A, Spitz M, Tan EK, Tayebi N, Toda T, Troiano AR, Tsuji S, Wittstock M, Wolfsberg TG, Wu YR, Zabetian CP, Zhao Y, \& Ziegler SG (2009) Multicenter analysis of glucocerebrosidase mutations in Parkinson's disease. N Engl J Med, 361, 1651-1661.
[27] Glik A, Masarwa M, Abuful A, Deeb A, Strugatsky R, Farrer LA, Friedland RP, \& Inzelberg R (2009) Essential tremor might be less frequent than Parkinson's disease in North Israel Arab villages. Mov Disord, 24, 119-122.

[28] Masalha R, Kordysh E, Alpert G, Hallak M, Morad M, Mahajnah M, Farkas P, \& Herishanu Y (2010) The prevalence of Parkinson's disease in an Arab population, Wadi Ara, Israel. Isr Med Assoc J, 12, 32-35.

[29] Anca M, Paleacu D, Shabtai H, \& Giladi N (2002) Crosssectional study of the prevalence of Parkinson's disease in the Kibbutz movement in Israel. Neuroepidemiology, 21, 50-55.

[30] Elbaz A, Bower JH, Peterson BJ, Maraganore DM, McDonnell SK, Ahlskog JE, Schaid DJ, \& Rocca WA (2003) Survival study of Parkinson disease in Olmsted County, Minnesota. Arch Neurol, 60, 91-96.

[31] Alves G, Muller B, Herlofson K, HogenEsch I, Telstad W, Aarsland D, Tysnes OB, \& Larsen JP (2009) Incidence of Parkinson's disease in Norway: the Norwegian ParkWest study. J Neurol Neurosurg Psychiatry, 80, 851-857.

[32] Grosset D, Taurah L, Burn DJ, MacMahon D, Forbes A, Turner K, Bowron A, Walker R, Findley L, Foster O, Patel K, Clough C, Castleton B, Smith S, Carey G, Murphy T, Hill J, Brechany U, McGee P, Reading S, Brand G, Kelly L, Breen K, Ford S, Baker M, Williams A, Hearne J, Qizilbash, \& N, Chaudhuri KR (2007) A multicentre longitudinal observational study of changes in self reported health status in people with Parkinson's disease left untreated at diagnosis. J Neurol Neurosurg Psychiatry, 78, 465-469. 